\title{
Peningkatan Aktivitas Dan Hasil Belajar PAIDBP Siswa Kelas IV Sekolah Dasar Melalui Penggunaan Model Discovery Learning
}

\author{
Fitria Aini*1, Yusrizal Efendi*2, Mega Adyna Movitaria*3 \\ ${ }^{1}$ UPTD SDN 02 Simpang Kapuak \\ ${ }^{1}$ LAIN Batusangkar \\ ${ }^{1}$ LAI Sumbar Pariaman \\ e-mail: ainifitria.1982@gmail.com, yusrizalefendi@iainbatusangkar.ac.id, \\ megaadyna@iaisumbar.ac.id
}

Submitted: 22-08-2021 Revised : 29-09-2021 Accepted: 23-10-2021

\begin{abstract}
This article to improve PAIdBP learning activities and learning outcomes for Class IV students of UPTD SDN 02 Simpang Kapuak for the 2020/2021 academic year by using the Discovery Learning model. This article is a Classroom Action Research (CAR) which was carried out in 2 cycles with 2 meetings for each cycle. The subjects in this study were grade IV students of UPTD SDN 02 Simpang Kapuak for the academic year 2020/2021, totaling 20 people. The data in this study were obtained through the use of observation sheets for teacher and student activities during the learning process and student learning outcomes at the end of each cycle. The data generated in this study were processed and analyzed descriptively qualitatively. The conclusion of the study shows that the use of the Discovery Learning model with the correct steps can increase the activity with average 78,78 and learning outcomes of Class IV PAIdBP students becomes 95\% UPTD SDN 02 Simpang Kapuak Academic Year 2020/2021.
\end{abstract}

Keywords:Islamic Education, Learning outcomes, Discovery learning, Character Education

\begin{abstract}
ABSTRAK. Artikel ini bertujuan meningkatkan aktivitas dan hasil belajar PAIdBP (Pandidikan Agama Islam dan Budi Pekerti) siswa Kelas IV UPTD SDN 02 Simpang Kapuak Tahun Pelajaran 2020/2021 dengan menggunakan model Discovery Learning. Artikel ini merupakan Penelitian Tindakan Kelas (PTK) yang dilaksanakan dalam 2 siklus dengan 2 kali pertemuan untuk masingmasing siklus. Subjek pada penelitian ini adalah siswa kelas IV UPTD SDN 02 Simpang Kapuak Tahun Pelajaran 2020/2021 yang berjumlah 20 orang. Data dalam penelitian ini diperoleh melalui penggunaan lembar observasi aktivitas guru dan siswa selama proses pembelajaran dan hasil belajar siswa pada akhir masing-masing siklus. Data yang dihasilkan dalam penelitian ini diolah dan dianalisis secara deskriptif kualitatif. Simpulan penelitian menunjukkan bahwa penggunaan model Discovery Learning dengan langkah-langkah yang benar dapat meningkatkan aktivitas dengan ratarata 78,79 dan hasil belajar PAIdBP menjadi 95\% siswa Kelas IV UPTD SDN 02 Simpang Kapuak Tahun Pelajaran 2020/2021
\end{abstract}

Keywords: Pendidikan Islam, Hasil Belajar, discovery learning, Pendidikan Budi Pekerti

Https://doi.org/10.54069/attadrib.v4i2.145

How to Cite Aini, F. Efendi, Y., Movitaria, M.A (2021). Peningkatan Aktivitas dan Hasil Belajar PAIdBP Siswa Kelas IV Sekolah Dasar melaluI Penggunaan Model Discovery Learning. Attadrib: Jurnal Pendidikan Guru Madrasah Ibtidaiyah, Volume (Issue), 55-61

\section{INTRODUCTION}

Pendidikan merupakan proses mendewasakan manusia. Menurut (Muttaqin, 2020) dengan pendidikan manusia bisa tumbuh dan berkembang secara wajar sehingga dapat melaksanakan tugas dan kewajibannya sebagai khalifah di permukaan bumi. Pendidikan mengubah semuanya. 
Pendidikan bisa mengubah manusia dari tidak tahu menjadi tahu, dari tidak baik menjadi baik (Andres, 2019; Baharun, 2015). Begitu penting pendidikan dalam Islam, sehingga merupakan kewajiban setiap orang. Guru adalah salah satu sumber yang harus menciptakan lingkungan belajar dengan suasana nyaman, kreatif dan membahagiakan untuk kegiatan belajar siswa (Deviyanti, 2021).

Guru merupakan faktor dan pelaksana penting dalam dunia pendidikan. Karena ia bertanggung jawab dalam pembentukan pribadi siswanya (Ambarsari et al., 2020). Oleh karena itu, guru merupakan orang dewasa yang bertanggung jawab memberi bimbingan atau bantuan kepada siswa dalam perkembangan jasmani dan rohaninya agar mencapai kedewasaannya, mampu melaksanakan tugasnya sebagai makhluk Allah, khalifah di permukaan bumi, sebagai makhluk sosial dan sebagai individu yang sanggup berdiri sendiri (Ariani, 2021).

Sedemikian penting peran guru, maka guru dituntut untuk kreatif dalam menarik minat siswa dalam belajar (Chairiyah, 2021). Sebagai penunjang pelaksanaan pembelajaran PAIdBP yang baik maka harus diperhatikan model, materi, strategi, dan metode pembelajarannya. Penekanan pada pelaksanaan proses pembelajaran sangat penting karena karakteristik pembelajaran dan materi muatan PAIdBP merupakan sebuah kajian ilmu praktek dan sikap, bukan hanya ilmu pengetahuan (konsep atau hafalan) (Juliayanto et al., 2021). Dan salah satu model yang dipakai adalah discovery learning.

Namun kenyataan yang terjadi di lapangan sering bertolak belakang dengan harapan pendidikan yang sebenarnya. Berdasarkan hasil refleksi guru selama semester 2 Tahun Pelajaran 2019/2020, siswa merasa bosan dan cenderung pasif, serta kurang fokus pada materi yang sedang dipelajari karena pembelajaran didominasi oleh metode ceramah guru, dan di akhir pembelajaran, siswa diminta untuk mengerjakan soal tanpa adanya aktivitas belajar yang menyenangkan. Berhubung karena aktivitas siswa selama pembelajaran hanya duduk dan mendengarkan penjelasan materi oleh guru, maka berdampak pada penguasaan materi, sehingga hasil belajar siswa menjadi rendah. Akhirnya siswa kelas IV banyak mengalami kesulitan belajar.

Hal ini dapat dilihat dari nilai Penilaian Harian $(\mathrm{PH})$ yang dilaksanakan pada materi Asmaul Husna dari 20 siswa, diketahui ada 8 orang siswa atau 40\% siswa yang belum mampu memperoleh nilai besar atau sama dengan KKM yang telah ditetapkan yaitu 75. Ini berarti hanya 12 orang atau $60 \%$ siswa yang lulus KKM (75), dengan nilai tertinggi adalah 85 dan nilai terendah 40. Gurusebagai peneliti memiliki harapan agar tes hasil belajar siswa dapat mencapai serta melebihi target KKM yang telah ditetapkan pada Satuan Pendidikan.

Setelah melakukan refleksi, menurut (Imron \& Saroi, 2020) guru menyadari bahwa salah satu faktor yang menyebabkan rendahnya hasil belajar siswa, adalah model pembelajaran yang digunakan guru masih kurang tepat dari harapan yang diinginkan sehingga motivasi belajar siswa menjadi rendah yang berakibat pada rendahnya hasil belajar yang diperoleh siswa. Kegiatan ceramah, selalu mendominasi pembelajaran. Kegiatan siswa terbatas pada mendengarkan ceramah guru, duduk tenang serta diusahakan tetap diam saat belajar (Aminah, 2020). Guru jarang memberi kesempatan dan stimulus pada siswa untuk bertanya. Hal ini terjadi karena guru terpaku dan hanya berpatokan pada LKS yang telah ada. Ketergantungan guru terhadap LKS meliputi materi dan tugas-tugas serta evaluasi yang dikerjakan. Pendekatan atau strategi pembelajaran yang digunakan guru dalam melaksanakan proses pembelajaran masih berorientasi pada pandangan pendidikan yang lama (Hidayat et al., 2020). Guru hanya berceramah, siswa mendengarkan serta, materi yang diajarkan terbatas pada materi yang ada di dalam buku paket.

Sesuai dengan masalah yang dijumpai pada pembelajaran PAIdBP siswa kelas IV UPTD SDN 02 Simpang Kapuak tahun pelajaran 2020/2021 maka diperlukan model pembelajaran yang tepat. (Huninhatu et al., 2021) menyatakan model pembelajaran merupakan kerangka konseptual yang melukiskan prosedur pembelajaran dengan sistematis untuk mengelola pengalaman belajar siswa agar tujuan belajar yang diinginkan bisa tercapai. 
Senada dengan pendapat di atas, (Hosnan, 2014) mengemukakan bahwa Discovery Learning adalah model belajar yang mendorong siswa untuk mengajukan pertanyaan dan menarik kesimpulan dari prinsip-prinsip umum praktis dan berdasarkan contoh pengalaman yang ada.

Selanjutnya (Mukaramah et al., 2020) juga berpendapat bahwa Discovery Learning atau belajar penemuan adalah belajar yang terjadi sebagian hasil dari siswa memanipulasi, membuat struktur dan mentransformasikan informasi sedemikian sehingga menemukan informasi baru. Dalam model Discovery Learning, siswa dapat membuat perkiraan (conjucture), merumuskan suatu hipotesis dan menemukan kebenaran dengan menggunakan proses induktif atau proses dedukatif, melakukan observasi dan membuat ekstrapolasi (Purwaningsih, 2020). Menurut (Utama \& Heldisari, 2021) Ciri utama belajar dengan model discovery learning, yaitu: (1) mengeksplorasi dan memecahkan masalah untuk menciptakan, menggabungkan, dan menggeneralisasikan pengetahuan; (2) berpusat pada peserta didik; (3) kegiatan untuk menggabungkan pengetahuan baru dan pengetahuan yang sudah ada.

Berdasarkan uraian di atas, rumusan masalah yang muncul yaitu (1) bagaimanakah langkahlangkah penggunaan model Discovery Learning yang dapat meningkatkan hasil belajar PAIdBP siswa kelas IV UPTD SDN 02 Simpang Kapuak?, (2) apakah penggunaan model Discovery Learning dapat meningkatkan hasil belajar PAIdBP siswa kelas IV UPTD SDN 02 Simpang Kapuak.

Tujuan penelitian ini yaitu (1) untuk mendeskripsikan langkah-langkah penggunaan model Discovery Learning dalam meningkatkan hasil belajar PAIdBP siswa Kelas IV UPTD SDN 02 Simpang Kapuak (2) untuk meningkatkan hasil belajar PAIdBP siswa Kelas IV UPTD SDN 02 Simpang Kapuak.

\section{METODE PENELITIAN}

Penelitian dilaksanakan di kelas IV UPTD SDN 02 Simpang Kapuak. Jumlah subjek penelitian 20 siswa yang terdiri atas 12 siswa laki-laki dan 8 siswa perempuan. Waktu penelitian dilaksanakan mulai bulan Juli 2020 sampai dengan bulan Desember 2020 pada semester satu tahun ajaran 2020/2021. Data yang digunakan dalam penelitian ini diperoleh dengan menggunakan instrumen tes dan non tes. Instrumen tes berupa lembar soal evaluasi hasil belajar siswa, sedangkan instrumen non tes terdiri dari lembar pengamatan aktivitas guru dan siswa selama proses pembelajaran.

Dalam melakukan penelitian ini, dibantu oleh 2 orang rekan guru yang bertindak sebagai pengamat/observer. Analisis data dilakukan dengan analisis deskriptif untuk membandingkan data kuantitatif berupa hasil belajar siswa setiap siklus dan analisis kualitatif yang mengacu pada pendapat Miles dan Hiberman meliputi tiga langkah kegiatan meliputi reduksi dan penyajian data, serta penarikan kesimpulan, yang dilakukan selama dan setelah pengumpulan data selesai (Sugiyono, 2015).

Prosedur penelitian yang digunakan dalam penelitian ini adalah metode penelitian tindakan kelas. Prosedur penelitian tindakan kelas meliputi rencana tindakan, pelaksanaan tindakan, pengamatan, serta refleksi. Dalam penelitian tindakan kelas ini digunakan model penelitian yang dikembangkan oleh (Arikunto, 2019) yang meliputi empat tahapan yang digunakan dan mencakup perencanaan, tindakan, observasi, dan refleksi. Dalam pelaksanaannya, tiap tahapan penelitian ini selalu berkaitan dan berkelanjutan dalam prosesnya, serta dilakukan perbaikan sesuai dengan hasil pengamatan/observasi serta refleksi hingga memenuhi hasil atau tujuan yang diharapkan. 


\section{HASIL DAN PEMBAHASAN}

\section{Hasil}

Proses pembelajaran tematik terpadu dengan penggunaan model Discovery Learning oleh guru yaitu bahwa pelaksanaan guru dalam mengajar pada siklus I sudah menunjukan langkahlangkah pembelajaran dengan model Discovery Learning sesuai dengan pendapat (Dari \& Ahmad, 2020) yaitu Stimulation (Pemberian Rangsangan), Problem Statement (Identifikasi Masalah), Data Collection (Pengumpulan Data), Data Processing (Pengolahan Data), Vericication (Pembuktian), Generalitation (penarikan kesimpulan). Peningkatan hasil belajar PAIdBP siswa Kelas IV UPTD SDN 02 Simpang Kapuak dengan menggunakan model Discovery Learning dilaksanakan dengan dua siklus. Masing-masing siklus dalam penelitian ini dilaksanakan sebanyak dua kali pertemuan, dengan alokasi waktu 4 jam pelajaran atau 4 x 35 menit.

Data rata-rata hasil observasi yang diperoleh dari dua orang observer terkait penggunaan desain pembelajaran model Discovery Learning pada pembelajaran tematik terpadu oleh guru pada siklus I sampai siklus II adalah sebagai berikut:

Table 1 Persentase Keterlaksanaan Model Discovery Learning pada Siklus I dan II

Langkah Model Discovery Learning

\begin{tabular}{|c|c|c|c|c|c|c|c|}
\hline \multicolumn{2}{|c|}{ Siklus I } & \multirow{2}{*}{$\begin{array}{c}\text { Rata-rata } \\
\text { Siklus I }\end{array}$} & \multicolumn{2}{|c|}{ Siklus II } & \multirow{2}{*}{$\begin{array}{l}\text { Rata-rata } \\
\text { Siklus II }\end{array}$} & \multirow[t]{2}{*}{ Rata-rata } & \multirow[t]{2}{*}{ Kategori } \\
\hline P1 & P2 & & P1 & P2 & & & \\
\hline 76,68 & 82,82 & 79,75 & 88,48 & 96,36 & 92,42 & 86,09 & Sangat Baik \\
\hline
\end{tabular}

Berdasarkan tabel 1 dapat disimpulkan bahwa persentase keterlaksanaan model Discovery Learning siklus I mencapai 79,75\%, sedangkan pada siklus II mencapai 92,42\%. Pelaksanaan langkah-langkah pembelajaran model Discovery Learning yang belum berjalan dengan baik berdampak pada aktivitas belajar siswa. Adapun hasil observasi penggunaan model Discovery Learning terhadap aktivitas siswa pada siklus I sampai siklus II dapat dilihat pada tabel berikut:

Table 2. Persentase Aktivitas Siswa pada Siklus I dan II

Langkah Model Discovery Learning

\begin{tabular}{|c|c|c|c|c|c|c|c|}
\hline \multicolumn{2}{|c|}{ Siklus I } & \multirow{2}{*}{$\begin{array}{c}\text { Rata-rata } \\
\text { Siklus I }\end{array}$} & \multicolumn{2}{|c|}{ Siklus II } & \multirow{2}{*}{$\begin{array}{c}\text { Rata- } \\
\text { rata } \\
\text { Siklus II }\end{array}$} & \multirow[t]{2}{*}{ Rata-rata } & \multirow[t]{2}{*}{ Kategori } \\
\hline P1 & $\mathbf{P} 2$ & & P1 & $\mathbf{P} 2$ & & & \\
\hline 66,67 & 72,73 & 69,7 & 84,85 & 90,91 & 87,88 & 78,79 & Baik \\
\hline
\end{tabular}

Dari tabel 2 dapat disimpulkan bahwa persentase penggunaan model Discovery Learning terhadap siswa pada siklus I mencapai 69,7\%, sedangkan pada siklus II mencapai 87,88\%. Faktor yang menjadi penghambat jalannya kegiatan pembelajaran pada siswa adalah faktor kesiapan siswa itu sendiri. Hasil penelitian ini sesuai dengan pendapat (Eskris, 2021) yang mengemukakan bahwa salah satu faktor intern dan berperan penting serta mempengaruhi pelaksanaan kegiatan pembelajaran adalah faktor kesiapan. Kegiatan belajar siswa pada siklus II juga sudah berjalan dengan lebih baik, siswa tampak lebih fokus pada materi yang sedang dipelajari dengan memanfaatkan media yang ada dan siswa sudah sangat antusias dalam berpendapat di kelas.

Sedangkan perolehan rata-rata nilai hasil belajar siswa pada siklus I dan siklus II adalah sebagai beikut:

Table 3. Perolehan Hasil Belajar PAIdBP Materi Asmaul Husna

Hasil Belajar Tematik Terpadu

\begin{tabular}{lcccc}
\hline \multirow{2}{*}{ Tindakan } & \multicolumn{2}{c}{ Tuntas } & \multicolumn{2}{c}{ Belum Tuntas } \\
\cline { 2 - 5 } & Frekuensi & Frekuensi & \% \\
\hline Siklus I & 12 & 60 & 8 & 40 \\
Siklus II & 19 & 95 & 1 & 5 \\
\hline
\end{tabular}

58 Attadrib: Jurnal Pendidikan Guru Madrasah Ibtidaiyah, Volume 4, Issue. 2, 2021, pp. 55-61 
Berdasarkan tabel 3 menunjukkan bahwa hasil belajar tematik terpadu siswa kelas IV semakin meningkat. Pada siklus I ketuntasan hasil belajar siswa mencapai $60 \%$ atau sebanyak 12 siswa. Pada siklus II meningkat menjadi 95\% atau sebanyak 19 siswa.

\section{Pembahasan}

Tingkat keberhasilan tindakan dalam penelitian ini adalah terjadinya peningkatan hasil belajar PAI siswa. Hasil penelitian ini menunjukkan bahwa hasil belajar PAI siswa dapat meningkatkan melalui metode discovery learning. Hal ini dapat dilihat dari peningkatan hasil belajar PAI siswa dan hasil tes belajar PAI siswa. Pembelajaran siswa aktif adalah bagian dari strategi pembelajaran yang mengarah pada pengeembangan keaktifan siswa dalam belajar, pengembangan keterampilan siswa dalam memproseskan pengetahuan, menemukan serta mengembangkan fakta, konsep pembelajaran (Putranto \& Ulfah, 2020).

Berdasarkan uraian yang telah dikemukakan tersebut dapat dinyatakan bahwa melalui metode discovery learning sangat efektif dalam peningkatan hasil belajar PAI. Akan tetapi berbagai kendala yang dihadapi haruslah menjadi acuan sebagai proses peningkatan hasil belajar siswa. Untuk itu penerapan pembelajaran aktif haruslah memenuhi kondisi-kondisi yang dipersyaratkan agar dapat diperoleh hasil yang optimal. Dengan menggunakan discovery learning hasil penelitian yang dilakukan melalui pembelajaran siswa secara keseluruhan terbukti sangat efektif dalam meningkatkan prestasi hasil belajar siswa. Untuk mencapai tujuan pembelajaran PAI secara utuh tidak cukup hanya dengan transfer pengetahuan dari guru kepada siswa, tetapi juga harus merangsang dan memotivasi siswa agar aktif dalam kegiatan belajar mengajar (Aliasmin, 2020).

Hal ini sejalan dengan yang diuraikan bahwa dengan menerapkan metode pembelajaran discovery learning dapat meningkatkan hasil belajar pendidikan agam Islam siswa (Sholeha, 2021).Siswa menemukan sendiri sesuatu hal yang baru. Cara belajar dengan menemukan (discovery learning) ini bukan merupakan cara belajar yang baru. Cara belajar melalui penemuan sudah digunakan puluhan abad yang lalu dan Socrates dianggap sebagai orang pertama yang menggunakan metode ini.Pengajaran ini mengharapkan agar siswa benar-benar aktif dalam belajar menemukan sendiri bahan yang dipelajarinya.

\section{KESIMPULAN}

Berdasarkan hasil analisis pelaksanaan penelitian, hasil penelitian dan pembahasan, maka dapat disimpulkan bahwa penelitian penggunaan model Discovery Learning yang dilaksanakan dengan langkah-langkah yang benar dapat meningkatkan hasil belajar siswa kelas IV dalam pembelajaran PAIdBP di UPTD SDN 02 Simpang Kapuak Tahun Pelajaran 2020/2021.

Selanjutnya, dari hasil penelitian di atas, peneliti memberikan saran kepada guru untuk menggunakan model Discovery Learning pada pembelajaran PAIdBP di kelas IV dan dikembangkan pada tingkatan kelas yang lain karena penggunaan model Discovery Learning dengan langkahlangkah yang benar terbukti dapat meningkatkan pembelajaran siswa. Dalam pelaksanaan pembelajaran dengan menggunakan model Discovery Learning guru juga disarankan untuk memperhatikan tiap langkah pembelajaran model Discovery Learning dan memperhatikan aktivitas belajar siswa sehingga suasana kelas menjadi kondusif.

Selanjutnya peneliti juga memberikan saran kepada sekolah hendaknya meningkatkan jumlah media pelajaran yang tersedia sehingga memudahkan guru dalam memberikan pengalaman belajar pada siswa dengan menggunakan model Discovery Learning. Sedangkan kepada siswa, peneliti memberikan saran agar lebih fokus dalam mengikuti kegiatan pembelajaran dengan menggunakan model Discovery Learning. Selain itu aktivitas belajar siswa selama proses pembelajaran lebih diarahkan dalam artian siswa lebih dilibatkan secara aktif serta supaya pelaksanaan kegiatan/proses pembelajaran dapat berjalan dengan lebih kondusif. 


\section{REFERENSI}

Aliasmin, A. (2020). Penggunaan Metode Discovery Learning Pada Pembelajaran PAI Untuk Meningkatkan Hasil Belajar Siswa Kelas VII SMP Negeri 10 Seluma. GHAITS A: Islamic Education Journal, 1(1), 42-48.

Ambarsari, D., Budyartati, S., \& Chasanatun, T. W. (2020). Strategi pembelajaran afektif dalam membentuk karakter bertanggung jawab siswa kelas 4 SDN Kledokan 1 Kecamatan Bendo Kabupaten Magetan Tahun ajaran 2019/2020. Prosiding Konferensi Ilmiah Dasar, 2, 69-77.

Aminah, S. (2020). Upaya guru dalam meningkatkan motivasi belajar siswa pada mata pelajaran Ilmu Pengetahuan Sosial di SMP Bahrul Maghfiroh Malang. Universitas Islam Negeri Maulana Malik Ibrahim.

Andres, H. P. (2019). Active teaching to manage course difficulty and learning motivation. Journal of Further and Higher Education, 43(2), 220-235. https://doi.org/10.1080/0309877X.2017.1357073

Ariani, N. (2021). Profesi Keguruan. Publikasi Pembelajaran, 1(2), 68-72.

Arikunto, S. (2019). Prosedurpenelitian. Rineka Cipta Publisher.

Baharun, H. (2015). Penerapan pembelajaran active learning untuk meningkatkan hasil belajar siswa di madrasah. PED AGOGIK: Jurnal Pendidikan, 1(1).

Chairiyah. (2021). Peran Guru Dalam Meningkatkan Minat Belajar Pendidikan Kewarganegaraan Menggunakan Media Flashcard Powerpoint Di SDN Berbah 2 Sleman. Jurnal Perseda: Jurnal Pendidikan Guru Sekolah Dasar, 4(1), 46-50.

Dari, F. W., \& Ahmad, S. (2020). Model Discovery Learning Sebagai Upaya Meningkatkan Kemampuan Berpikir Kritis Siswa SD. Jurnal Pendidikan Tambusai, 4(2), 1469-1479.

Deviyanti, L. (2021). Upaya Guru Pendidikan Agama Islam (PAI) dalam Meningkatkan Konsentrasi Belajar Peserta Didik Kelas IV di SD Negeri 44 Pontianak. Tarbawi Khatulistiwa: Jurnal Pendidikan Islam, 6(1).

Eskris, Y. (2021). Meta Analisis Pengaruh Model Discovery Learning dan Problem Based Learning terhadap Kemampuan Berfikir Kritis Peserta didik Kelas V SD. Mahaguru: Jurnal Pendidikan Guru Sekolah Dasar, 2(1), 43-52.

Hidayat, H., Mulyani, H., Arifin, N. N., \& Rahmawati, N. S. (2020). Pembelajaran Pendidikan Kewarganegaraan melalui Pendekatan Pembelajaran Kooperatif Tipe Student Team Achievement Divisions di Sekolah Dasar. Jurnal Pendidikan Kewarganegaraan, 4(1), 106-115.

Hosnan. (2014). Pendekatan Saintifik dan Kontekstual dalam Pembelajaran Abad 21. Ghalia Indonesia.

Huninhatu, A. F., Pudjiastuti, S. R., \& Sutisna, M. (2021). Pengembangan Model Numbered Heads Together Secara Daring dalam Meningkatkan Pemahaman Nilai Pancasila dan Pembentukan Karakter Disiplin. Jurnal Citizenship Virtues, 1(1), 35-41.

Imron, M., \& Saroi, J. (2020). Pengaruh Model Problem Based Learning terhadap Kompetensi Belajar Biologi Siswa. Biolearning Journal, 7(2), 70-74.

Juliayanto, W., Auliya, H., \& Rubiyad, A. (2021). Konsep Pendidikan Islam Menurut KH. Yahya Masduqi. MASILE, 1(1), 240-262.

Mukaramah, M., Kustina, R., \& Rismawati, R. (2020). Menganalisis Kelebihan dan Kekurangan Model Discovery Learning Berbasis Audiovisual dalam Pelajaran Bahasa Indonesia. Jurnal Ilmiah Mahasiswa Pendidikan, 1(1). 
Muttaqin, M. (2020). Konsep Pendidikan Islam dalam Keluarga Menurut Zakiah Daradjat. Jurnal TAUJIH, 13(02).

Purwaningsih, E. (2020). Penerapan Model Pembelajaran Discovery" Triple B-Net" pada Pelajaran Karakteristik Negara Maju dan Negara Berkembang Dunia sebagai Upaya Meningkatkan Kreativitas Belajar Siswa. Metafora: Education, Social Sciences and Humanities Journal, 2(4), 105-114.

Putranto, D., \& Ulfah, W. A. (2020). Pengembangan Model Pembelajaran Gerak Multilateral Berbasis Role Playing Game (RPG) pada Siswa Sekolah Dasar. Riyadhob: Jumal Pendidikan Olahraga, 3(2), 17-25.

Sholeha, D. (2021). Upaya Peningkatan Hasil Belajar Siswa Melalui Metode Pembelajaran Discovery Learning. Indonesian Journal of Teacher Education, 2(1), 218-225.

Sugiyono. (2015). Metode Penelitian Pendidikan Pendekatan Kuantitatif, Kualitatif, dan R \& D. Alfabeta.

Utama, D. G., \& Heldisari, H. P. (2021). Pembelajaran Dinamika pada Ansambel Gitar Ditinjau dari Aspek Afektif, Kognitif, dan Psikomotor. Journal of Music Education and Performing Arts, 1(1), 16-22. 